\title{
Em análise a cooperação "Sul-Sul": ruptura ideológica ou reprodução?
}

\author{
Danielle Regina Ullrich' \\ Rosinha da Silva Machado Carrion ${ }^{2}$
}

\section{Resumo}

O modelo Norte-Sul de cooperação internacional para o desenvolvimento, cuja origem remete ao período pós Segunda Guerra Mundial, apoiou-se, historicamente, em um discurso que atribuía aos países centrais, ou do "Norte", dada sua maturidade institucional e superioridade técnica, legitimidade para definirem as regras e os procedimentos a serem observados pelos países na periferia do sistema mundo, para acederem ao propalado "desenvolvimento". Modelo este que, conforme um contingente significativo de pesquisadores (BARBANTI JUNIOR, 2005; SANTOS FILHO, 2005; AFONSO; FERNANDES, 2005; SÁNCHEZ, 2002), contemplaria, essencialmente, objetivos de natureza econômica e política das potências centrais. Todavia, ao conquistarem reconhecimento econômico no plano internacional, países emergentes como o Brasil, Índia, China, Rússia e África do Sul estariam estabelecendo, entre si, assim como com outros países do "Sul", relações de parceria e cooperação às quais, também conforme um contingente expressivo de pesquisadores (XALMA, 2011; PUENTE, 2010; AYLLÓN PINO, 2012), se distinguiriam do modelo anterior pela ênfase atribuída a valores como a solidariedade e a equidade, no que tange à distribuição equitativa dos benefícios entre os países envolvidos nas ações de cooperação. De natureza teórica, o presente artigo questiona, em que medida essa tese se sustenta? Ou, dizendo de outro modo, em que medida o modelo de cooperação internacional Sul-Sul associado à promoção do desenvolvimento constitui-se em uma ruptura paradigmática com o modelo de cooperação Norte-Sul?

Palavras-chave: Cooperação Internacional. Cooperação Sul-Sul. Desenvolvimento.

1 Doutoranda em Administração pela Universidade Federal do Rio Grande do Sul (UFRGS), Porto Alegre, Rio Grande do Sul, Brasil. É autora de artigos publicados nas revistas: Invenio (Rosario), 20 I3; Desenvolvimento em Questão, 2012; REGE. Revista de Gestão USP, 2012, entre outras. E-mail: danielle_ullrich@yahoo.com.br. A autora agradece ao Conselho Nacional de Desenvolvimento Científico e Tecnológico (CNPq) por financiar este trabalho por meio da concessão de bolsa de doutorado.

2 Doutora em Sociologie Clinique na Université de Paris VII (Jussieu-Sorbonne) e em Administração pela Universidade Federal do Rio Grande do Sul - UFRGS (1998) Porto Alegre. Brasil. Pós-Doutora pelo Institute de Recheche Pour le Développement (2011/Université de Paris I/Sorbonne) e Professora Associada da UFRGS. É autora de artigos publicados nas revistas: Desenvolvimento em Questão, 2012; Cadernos EBAPE.BR (FGV), 2012; Revista de Economia E Relações Internacionais, 201 I, entre outras.E-mail: rsmcarrion@ea.ufrgs.br. 


\section{Introdução}

A partir da abordagem do sistema-mundo de Wallerstein (2000), segundo a qual os países centrais impóem sua visão de mundo aos países periféricos e semiperiféricos, percebe-se que, além de uma dominaçáo econômica, há uma dominação ideológica que reproduz a lógica colonialista. Teóricos da corrente neocolonial, como Quijano (2005), Dussel (2005), Mignolo (2005), Lander (2005) e Grosfoguel (2008), apontam que o exercício da dominação exercida pelos países centrais sobre os periféricos náo se limita ao campo econômico estendendo-se para o social, o cultural, o étnico, via a difusão da ideologia colonialista. A qual, baseada em uma visáo eurocêntrica de mundo, legitima certo modelo de desenvolvimento e certa representaçáo do mundo, desfavoráveis tanto à consolidaçáo econômica e à possibilidade real de desenvolvimento, como à soberania política dos países periféricos e semiperiféricos.

$\mathrm{Na}$ contracorrente dessa vertente, estaria em curso na última década, e sob a liderança das chamadas novas potências emergentes, um novo padráo de relaçóes internacionais de cooperação, caracterizado por relaçóes mais equilibradas e democráticas, baseadas no respeito e no compartilhamento de saberes. O compartilhamento e a valorização dos saberes, conforme apontado por Barbanti Junior (2005), constituem-se na mola propulsora, ou filosofia de base, desse novo modelo de cooperaçáo para o desenvolvimento.

De natureza teórica, o presente artigo questiona em que medida o modelo de cooperaçáo que vem sendo praticado entre países semiperiféricos e periféricos ("Sul-Sul") é inovador no que tange tanto ao modo de construção do desenvolvimento como ao lugar a ser atribuído nesse processo à questáo dos saberes.

Sintomas de profundas mudanças existem. Conforme apontam Arrighi e Silver (2001, p. 30), o sistema internacional vive um momento singular:

Podemos tomar a falta de consenso quanto à direção e ao sentido das atuais mudanças na economia política global como um sinal de que estamos em meio a uma mudança sistêmica - ou seja, um processo de reorganização radical do moderno sistema mundial que altera substantivamente a natureza dos integrantes do sistema, sua maneira de se relacionar uns com os outros, e o modo como o sistema funciona e se reproduz.

Deste modo, questiona-se: o modo como vem se processando a cooperaçáo entre países do Sul faria parte desse conjunto de mudanças radicais 
anunciadas por Arrighi e Silver (2001)? Ou, pelo contrário, ainda que distinta na forma e, eventualmente, nas estratégias, estar-se-ia diante da reproduçáo do velho modelo de cooperação Norte-Sul?

Para Sousa Santos (2009), a hegemonia do pensamento moderno ocidental continua a alimentar um sistema de exclusâo, que divide o mundo entre Ocidente e Oriente, entre Norte e Sul, acentuando a realidade de exclusáo característica do período colonial. Conforme ele, para superar essa situaçáo seria preciso romper com a lógica que divide o mundo em centro e periferia e que ele classifica como "pensamento abissal". Pensamento esse que concede à ciência moderna o monopólio do direito de definir o que é verdadeiro e o que é falso, em detrimento de outros tipos de conhecimento, nâo aceitos pelo paradigma científico hegemônico. Conforme denuncia o sociólogo português, o espaço ocupado no imaginário contemporâneo pelo paradigma científico eurocêntrico inviabiliza o reconhecimento de formas alternativas de conhecimento. De tal modo que o pensamento abissal separaria, de um lado, a ciência e, de outro, saberes tornados incomensuráveis e incompreensíveis por náo se pautarem pelos critérios científicos institucionalizados. Para superar essa situaçáo seria preciso - sem desconsiderar os aportes da ciência moderna - promover uma verdadeira "ecologia de saberes" (SOUSA SANTOS, 2008). Isto é, assegurar o reconhecimento em pé de igualdade dos saberes ocidentais, hoje hegemônicos, e dos saberes locais condenados, no presente, à subalternidade.

Conforme Xalma (2011) e Puente (2010), a cooperaçáo recente entre países do "Sul" estaria privilegiando valores, tais como: a complementariedade e o respeito à diversidade de saberes; a valorizaçáo das habilidades e das competências locais; o compartilhamento de experiências e a construçáo conjunta de tecnologias. Conjunto esse de fatores que configuraria um novo patamar de cooperaçáo distinto do modelo que historicamente caracterizou as relaçóes de cooperaçáo entre o centro e a periferia. Modelo esse que, como aponta Grosfoguel (2008), traduz a dominaçáo, nas áreas econômica, social e cultural, pelos países centrais.

\section{Cooperação Internacional para o “Desenvolvimento" e o discurso desenvolvimentista}

Conforme Barbanti Junior (2005), no período de dominaçáo colonial do mundo, o conceito de desenvolvimento esteve atrelado à concepçáo 
darwiniana de evolução e progresso. Santos Filho (2005) afirma que, até a Segunda Guerra Mundial, cabia aos países colonizadores a promoçáo do desenvolvimento das colônias, processo esse realizado conforme e de acordo com as necessidades econômicas e os interesses políticos dos países centrais. $\mathrm{O}$ desenvolvimento entendido como um processo a ser alcançado a partir da passagem dos países "subdesenvolvidos" por um conjunto de estágios, a serem galgados conforme regras previamente concebidas pelos países do "Norte", autoclassificados como "desenvolvidos", em funçáo de seu grau de avanço tecnológico, da acumulaçáo econômica conquistada e de outros critérios igualmente positivistas. A trajetória rumo à modernidade ou ao "desenvolvimento" se daria, assim, via a observaçâo de regras e do cumprimento de estágios específicos. Os projetos de dominaçáo colonial apresentados, como aponta Carrion et al. (2012), como missão civilizadora teriam por objetivo retirar os países classificados como subdesenvolvidos do estado de barbárie e de miséria no qual se encontravam.

Após a Segunda Guerra Mundial, a dinâmica da cooperaçáo Norte-Sul será balizada pelo discurso de posse do presidente dos Estados Unidos, Harry S. Truman (BARBANTI JUNIOR, 2005). De caráter profundamente dualista, o referido discurso dividiria o mundo entre, de um lado, os países autoclassificados desenvolvidos e, de outro, os por ele classificados de subdesenvolvidos, cabendo aos países do "Norte", ricos e "desenvolvidos", levar aos países do Sul, pobres e subdesenvolvidos, as maravilhas do avanço científico e do progresso técnico e industrial, por eles conquistados.

Ainda, conforme Barbanti Junior (2005, p. 143), "o caráter de transferência do conhecimento científico e do know-how industrial passou a conferir, até os dias atuais, a orientaçáo principal das intervençóes internacionais para o desenvolvimento".

De acordo com Grosfoguel (2008), a visão de desenvolvimento, assim concebida, seria apresentada à sociedade como resultado do conhecimento científico, o que em um período histórico em que reinava a visão racional do mundo e da vida, seria sinônimo de verdade absoluta. $\mathrm{O}$ que, em outras palavras, significa dizer: uma visâo ocidental do mundo, que tinha por religiáo o progresso e por credo o ideário capitalista apresentado como o único capaz de assegurar o progresso técnico e o "desenvolvimento". 
Conforme Afonso e Fernandes (2005), o modelo de cooperação Norte-Sul se constrói à sombra de um conjunto de fatores, ou "temores", que assombravam os países vitoriosos na Segunda Guerra Mundial: uma nova guerra, a reprodução da depressão econômica dos anos 1929-1930 e o receio do avanço do ideário comunista. Conjunto de fatores que explicaria porque as questóes de segurança militar e de estabilidade econômica e social nos países do Sul tenham sido tomadas como prioridades e pautado o caráter das relaçóes interestados. O medo do avanço soviético faria, todavia, com que as questôes de segurança se sobrepusessem às de natureza social.

Conforme Sánchez (2002), o desejo de impedir que os países do Sul caíssem sob a zona de influência da Uniāo das Repúblicas Socialistas Soviéticas (URSS) explicaria o caráter profundamente interventor; de dominaçáo vertical; exógeno (imposto de fora); unilateral (uma das partes decide); e parcial (privilegiando os interesses de quem concede a ajuda), das medidas de cooperaçấo internacional para o desenvolvimento levadas a efeito no período.

Já Afonso e Fernandes (2005) destacam o papel atribuído ao empresariado dos países apoiados no processo de promoçáo do desenvolvimento dos países do "Sul". Assim, se ao "Norte" cabia definir o que era o "progresso", como promover o desenvolvimento e aportar os recursos financeiros para tal, caberia àqueles organizar e promover a produçáo em moldes capitalistas.

A visáo de desenvolvimento, que dividia o mundo em países desenvolvidos e países subdesenvolvidos, sofreria, todavia, um forte revés na década de 1970, com a publicaçáo da obra "Dependência e Desenvolvimento na América Latina: ensaio de interpretaçáo sociológica", escrita por Fernando Henrique Cardoso, em seus anos de exílio, em coautoria com Enzo Faletto. Na obra, eles sustentavam que, se a América Latina se encontrava em uma posição desfavorável em termos econômicos e sociais, devia-se o fato aos anos de exploraçáo histórica dos países do continente latino-americano pelas potências centrais, argumentando, ainda, ser destituída de sentido a "Teoria das Etapas do Desenvolvimento" elaborada por Rostow (1960) e que fornecera a fundamentaçáo teórica para o modelo dos estágios de passagem rumo ao desenvolvimento, imposto aos países do "Sul" pelas potências do "Norte". A tese defendida por Cardoso e Faletto (1984) sustentava que a causa do subdesenvolvimento dos países periféricos (atrasados) radicava nas relaçóes de dominação e no padrão de exploração da relação centro-periferia. 
A partir de meados dos anos 1980, com o desequilíbrio da balança de pagamento e o agravamento da dívida externa nos países periféricos, as condicionalidades impostas pelos países ricos para o financiamento do desenvolvimento centraram-se em questóes de natureza macroeconômica (AFONSO; FERNANDES, 2005). Como bem aponta Sánchez (2002), os recursos repassados aos países subdesenvolvidos e/ou em subdesenvolvimento, a partir de entâo, foram condicionados ao cumprimento de uma série de medidas e ajustes de natureza neoliberal urdidos no Consenso de Washington.

Conforme Grosfoguel (2008), o período foi marcado pela supervisão leia-se intervençáo direta - do Fundo Monetário Internacional e do Banco Mundial na economia dos países periféricos. Processo esse que se caracterizou pela imposiçấo de regulaçóes econômicas de cunho neoliberal, as quais, como aponta Carrion (2009), foram responsáveis pela desestruturação da economia de países que apresentavam fragilidades econômicas, como o Senegal, que teve sua economia destruída pelos Programas de Ajuste Estrutural (PAS) impostos pelo Banco Mundial e pelo Fundo Monetário Internacional na década de 1980 .

Na década de 1990, com o final da Guerra Fria, o evidente fracasso dos PAS e os primeiros sintomas da crise que viria assolar as economias centrais, os termos da cooperaçáo internacional seriam revistos (SÁNCHEZ, 2002). Questôes como a estrutura interna dos governos, a necessidade de superar os entraves burocráticos locais, assim como a luta contra a corrupçáo, são os novos argumentos utilizados para legitimar a reforma do aparato administrativo dos Estados apoiados a fim de ajustá-los à necessidade de circulação dos capitais globalizados (CARRION et al., 2012).

Evidencia-se, da análise anterior, que a chamada cooperação Norte-Sul foi, historicamente, alimentada pela vontade política de proteger e consolidar os interesses políticos e econômicos das potências centrais, e que nesse jogo diplomático os interesses dos países do "Sul" tiveram um papel secundário. As intençóes, náo claramente reveladas dos países centrais, de imprimirem seu "modelo" de desenvolvimento aos países semiperiféricos e periféricos surtiram, na maior parte das vezes, em benefícios para os próprios países doadores, e poucos sáo os resultados positivos no sentido lato da palavra desenvolvimento, da cooperaçáo internacional Norte-Sul para o desenvolvimento dos países semiperiféricos e periféricos. 
No período mais recente vem, todavia, se observando a intensificação de acordos, bem como a consolidaçáo de alianças entre países do Sul, o que, se náo chega a ser uma novidade, tem um conteúdo inovador quando se tem em conta o sentido estratégico dessas alianças para a consolidação política no cenário internacional de países, como o Brasil, que vem sendo apontado como uma nova "potência emergente". Esse é o tema da próxima seção.

\section{Cooperação entre países periféricos e semiperiféricos ("Sul-Sul”)}

Conforme Puente (2010), a cooperaçáo entre países semiperiféricos e periféricos, também chamada de Sul-Sul (CSS) ou cooperação horizontal, ou ainda, cooperaçáo técnica entre países em desenvolvimento (CTPD), é um fenômeno recente, que remete à década de 1970, período no qual ganharam força as iniciativas de afirmação dos países do "Sul" (semiperiféricos e periféricos) no cenário internacional, em decorrência da percepçáo de que as relaçóes "Norte-Sul" se assentavam sobre uma lógica prejudicial aos seus interesses.

Ainda para Puente (2010), o desgaste das relaçóes "Norte-Sul" conduziu a uma série de questionamentos, pelos países do "Sul", da ordem econômica internacional vigente, os quais passariam, nos foros multilaterais, a expressar a crescente convicçáo de que não lhes restavam muitas alternativas a náo ser promover entre si maior concertaçáo no intuito de buscar o fortalecimento de sua posiçáo com relação aos países centrais.

Historicamente, os princípios da CSS começaram a ser delineados em 1977, durante a 32a Sessáo da Assembleia Geral das Naçóes Unidas (ONU). Conforme Xalma (2011), pela primeira vez, uma resolução da ONU buscou definir os objetivos e os princípios da entáo chamada Cooperaçáo Técnica entre Países em Desenvolvimento (CTPD). A intençáo, conforme ficou definido, seria promover alianças bilaterais entre os chamados países em desenvolvimento. Conforme Puente (2010), durante essa conferência, nasceu o Grupo dos 77, o qual reunia países semiperiféricos e periféricos interessados em reforçar sua posiçáa mediante a identificaçáo de pontos de interesse comum e da proposiçáo de medidas concretas que pudessem alterar as condiçóes do comércio internacional, consideradas desvantajosas para os países do "Sul". $\mathrm{O}$ próprio modelo de cooperaçáo para o desenvolvimento passou, também, 
a ser questionado, por estar assentado sobre bases ora assistencialistas, ora de dominação conectadas a interesses comerciais dos países do centro.

Segundo Puente (2010), a Conferência de Buenos Aires, em 1978, representou o primeiro esforço coletivo de identificação e de sistematização das formas, modalidades e possibilidades de cooperaçáo entre países em desenvolvimento. O surgimento da cooperação entre países semiperiféricos e periféricos decorreu das frustraçóes desses países com o modelo de cooperaçáo ora vigente, bem como da conscientizaçáo de que eles deveriam ser parceiros entre si no processo de construção de soluçóes para os seus problemas e náo apenas recipiendários passivos de ajuda externa imposta pelo "Norte". A cooperaçáo Sul-Sul se configuraria, assim, como estratégia alternativa e complementar, e náo necessariamente excludente à cooperação tradicional, imposta pelo centro.

Após os avanços obtidos pela CSS na década de 1970, Puente (2010) afirma que a crise dos anos 1980 teria provocado um período de estagnaçáo. Assolados pela dívida interna, os países semiperiféricos não disporiam de recursos para financiar os projetos de cooperaçáo. Como se sabe, por imposição do Fundo Monetário Internacional (FMI), o período pós a chamada "década perdida" foi acompanhado da implementaçáo de programas de ajustamento ortodoxos, com cortes nas despesas públicas, fazendo com que os recursos para financiar iniciativas de desenvolvimento praticamente deixassem de existir.

A partir da década de 1990, com a aceleração da globalização, novos desafios se colocaram à CSS, e passaram a exigir de todos os países, mas especialmente dos semiperiféricos, que buscassem novas formas de inserçáo na arena internacional. Conforme aponta Visentini (2008, p. 1), "a globalização gerou espaços para a projeção de potências regionais, líderes de blocos econômicos, o que contribui para reforçar a possibilidade de formaçáo de um sistema mundial multipolar, em lugar de uma neo-hegemonia norte-americana”.

Com o objetivo de minimizar os riscos e maximizar as oportunidades associadas ao processo de globalização, Puente (2010) afirma que os países privilegiaram a estratégia da CSS. Em especial, por recomendação do Programa das Naçóes Unidas para o Desenvolvimento (PNUD) e, também, pela iniciativa de alguns países do Sul, reforçou-se o discurso da CSS nos foros internacionais a partir dos anos 2000. 
O traçado histórico e as discussōes sobre a CSS consolidaram-na como uma modalidade de cooperaçáo que contempla três dimensôes: (i) dimensão política, que promove a constituiçáo de âmbitos autônomos para a geraçáo de perspectivas e práticas alternativas entre países semiperiféricos e periféricos; (ii) dimensão técnica, processo pelo qual países semiperiféricos e periféricos adquirem capacidades individuais e coletivas através de intercâmbios cooperativos em conhecimentos, experiências tecnológicas, expertises tecnológicas, que se traduzem em projetos e programas de cooperaçáo; (iii) dimensão econômica, realizada no âmbito comercial, financeiro e de investimentos entre países semiperiféricos e periféricos (AYLLÓN PINO, 2012).

Conforme Xalma (2011), há consenso geral de que o principal valor acrescentado pela cooperação Sul-Sul é sua contribuição para o desenvolvimento e reforço das capacidades entre os parceiros em uma relaçâo horizontal em que ambos se beneficiam. O desenvolvimento ocorreria mediante a troca de conhecimento, de tecnologias e experiências, do incentivo à produção, do uso do conhecimento local, das habilidades e das competências, bem como da sistematizaçáo e análise de experiências bem-sucedidas.

\section{O moderno sistema-mundo e a dominação ideológica na cooperação internacional para o desenvolvimento}

Conforme já informado, o presente artigo tem por objetivo analisar em que medida o modelo de cooperação Sul-Sul apresenta-se como uma ruptura paradigmática quando comparado ao modelo de cooperaçâao Norte-Sul.

Conforme Wallerstein (2000), o moderno sistema-mundo, responsável pelo modelo de cooperaçáo Norte-Sul, surgiu como parte de um processo em que houve a expansão da economia mundial capitalista e da relaçáo desta com um sistema interestatal. No final do século XIX, esse sistema, por meio da integraçáo do processo de trabalho, alastrou-se pelo globo, cobrindo-o, dando origem ao primeiro sistema-mundo na história a conseguir este feito.

Wallerstein (2000) identifica no moderno sistema-mundo a existência de múltiplos centros políticos, que estáo em uma constante e complexa luta interestatal pela hegemonia do sistema. O sistema interestatal envolve uma estrutura política composta de Estados. Este sistema tem sido governado por um longo e cíclico processo chamado de ciclo hegemônico. A situação ideal, 
em termos de acumulação de capital para o sistema, é a existência de um poder hegemônico, forte o suficiente para definir as regras do jogo e ser seguido pelos demais países. Conforme Arrighi (2003), o sistema capitalista passou por quatro ciclos sistêmicos de acumulação e expansão que tiveram suas hegemonias, a saber: o genovês, o holandês, o britânico e o estadunidense.

Desse modo, segundo Wallerstein (2000), o moderno sistema-mundo, construído sobre a divisão do trabalho e o sistema interestatal, gerou a distribuiçáo desigual de seu produto entre as regióes, que participam da produçáo mundial. As atividades mais lucrativas tendem a ficar concentradas, geograficamente, em pequenas áreas da economia mundial, chamada de zona central (core zone). As atividades menos lucrativas têm suas unidades de atividade econômica dispersas geograficamente, localizadas numa área abrangente, chamada de zona periférica (peripheral zone).

De acordo com Cobério (2008), a transferência sistemática dos excedentes das regióes periféricas para as centrais, juntamente com a necessidade dos capitalistas das regióes centrais garantirem o monopólio de suas atividades econômicas mediante alianças com o Estado, gera uma distribuição assimétrica do produto do sistema, mecanismo pelo qual o excedente é retirado das periferias e concentrado no centro.

Todavia, Grosfoguel (2008) argumenta que a análise dos economistas políticos restringe-se à dimensáo econômica e que a dominaçáo exercida pelos países centrais sobre os países semiperiféricos e periféricos, também, ocorre em dimensōes como a social e a cultural. Assim como Wallerstein (2004), Grosfoguel (2008) defende que, em sua origem, o sistema-mundo foi produzido a partir da expansáo colonial europeia, cujo objetivo era encontrar rotas mais curtas para o Oriente, o que, acidentalmente, levou à colonização da África e das Américas. Segundo esse ponto de vista, o sistema-mundo capitalista seria, essencialmente, um sistema econômico que determina o comportamento dos principais atores sociais pela lógica econômica da obtençáo de lucro, manifestando-se na extração de excedentes e na incessante acumulação de capital à escala mundial. A análise de classes e as transformaçóes estruturais no âmbito econômico são privilegiadas em relaçáo a outras relaçóes de poder, que se configuram neste âmbito.

Grosfoguel (2008) argumenta ainda que a colonização europeia não expandiu apenas um sistema econômico de capital e trabalho. Essa foi uma 
parte fundamental, ainda que não a única, de um "pacote" mais complexo e enredado. Destaca-se que uma abordagem redutora da perspectiva econômica do sistema-mundo náo é capaz de explicar que a colonizaçáo levou consigo a imagem do homem heterossexual/branco/patriarcal/cristáo/militar/capitalista/ europeu, com as suas várias hierarquias globais enredadas e coexistentes no espaço e no tempo. Ou seja, a dominação não foi apenas no campo econômico, mas também no social e cultural.

Dentro da concepçáo de dominaçáo ideológica, Arrighi (2003) aponta dois fatores fundamentais no moderno sistema-mundo: primeiro, que as relaçóes de poder dentro e entre os Estados ocidentais têm sido moldadas pelas relaçóes de poder entre os Estados ocidentais e o mundo náo ocidental, e, em segundo, aquilo em que os Estados, ocidentais e náo ocidentais, têm se tornado é, em grande medida, o resultado de um processo da conquista do mundo pelos Estados europeus. Esse processo materializou-se de forma mais evidente com a globalização. Embora o centro de sistema expansivo tenha "migrado" de país para país na Europa e, finalmente, para a América do Norte, ele permaneceu dentro de uma zona cultural comum, que excluiu os países africanos, latino-americanos e asiáticos. Mesmo que as instituiçóes econômicas e políticas do centro tenham passado por transformaçóes significativas, elas permaneceram dentro de uma tradição culturalmente ocidental.

Assim, Grosfoguel (2008) atesta que continuamos a viver sob a mesma "matriz de poder colonial". A descolonizaçáo jurídico-política significa apenas que saímos de um período de "colonialismo global", para entrar num período de "colonialidade global". Embora as "administraçóes coloniais" tenham sido quase todas erradicadas, e grande parte da periferia tenha se organizado politicamente em Estados independentes, os povos náo europeus continuam a viver sob a exploração e dominação europeia/euro-americana. As antigas hierarquias coloniais, agrupadas na relação "europeias versus não europeias", continuam arraigadas e enredadas na "divisáo internacional do trabalho" e na acumulação do capital à escala mundial.

Tal embate permeia as discussóes sobre a cooperação internacional para o desenvolvimento, que, segundo Barbanti Junior (2005), ainda hoje tem como orientação principal a transferência do conhecimento científico e do know-how industrial, dos países centrais para os países semiperiféricos e periféricos. Wallerstein (2000) aponta que é a tecnologia que sustenta a expansão 
do sistema mundial de produção, ou seja, a fé na ciência, baseada na habilidade dos cientistas em contribuir com as mudanças tecnológicas. Desde a metade do século XIX, o universalismo tornou-se o valor central de organizaçáo da economia mundial capitalista. A ciência passou a reger as leis universais, para as quais os resultados oriundos das pesquisas seriam iguais, para processos idênticos.

Assim, a questão do compartilhamento de saberes, como condiçáo do desenvolvimento no campo da cooperaçáo internacional, evidencia dois mitos que, de acordo com Ribeiro (2009), ainda parecem persistir nos estudos desta área. $\mathrm{O}$ primeiro mito diz respeito à concepçáo de desenvolvimento como um caminho linear a ser perseguido a partir da experiência dos países desenvolvidos. O segundo é a crença que os conhecimentos disponíveis nos países do centro podem ser transferidos e aplicados, sem a devida redução sociológica, de maneira universal. Esses dois princípios partem do pressuposto de que tanto a ideia de desenvolvimento como de ciência seriam neutras e que o avanço da ciência traria, necessariamente, o progresso para todos.

Conforme Sousa Santos (2008), o conhecimento científico e tecnológico eurocêntrico ainda é considerado a forma privilegiada de conhecimento. Desde o século XVII, as sociedades ocidentais têm privilegiado, epistemológica e sociologicamente, a forma de conhecimento designada por ciência moderna. A predominância do conhecimento oriundo do Ocidente e de países centrais também é reforçada pelos pressupostos da reorganizaçáo global da economia capitalista, que se assenta, entre outros fatores, na produçáo contínua e persistente de verdades epistemológicas, que náo reconhecem a existência, em pé de igualdade, de outros saberes, do que resulta uma hierarquia epistemológica geradora de marginalizaçóes, silenciamentos ou exclusóes de outros conhecimentos.

Isto fica evidente, segundo Ribeiro (2009), ao desconsiderar-se a existência de valores sociais e interesses econômicos implícitos na produçáo do conhecimento científico e tecnológico, bem como as consequências de sua aplicação em contextos histórico-culturais específicos. A "crença" na neutralidade da ciência e na "universalidade" dos indicadores de desenvolvimento continua a orientar a elaboraçáo de políticas de desenvolvimento, tanto nos países centrais como nos países semiperiféricos e periféricos.

A universalidade da ciência e sua imposição como verdade única é um dos fatores que contribuem para a dominação ideológica exercida pelos países 
centrais sobre os países semiperiféricos e periféricos. Para Sousa Santos (2009), o pensamento moderno ocidental é fraturante, é um pensamento abissal, como uma linha que separa dois mundos, cuja característica principal é a impossibilidade da copresença dos dois lados da linha. Um lado da linha impóe sua visão de mundo, postulando que para além dela há apenas inexistência, invisibilidade e ausência.

Grosfoguel (2008) corrobora ao afirmar que os paradigmas eurocêntricos hegemônicos assumem um ponto de vista universalista, neutro e objetivo, para os quais a ciência é conduzida sempre a partir de uma determinada hierarquia do "sistema-mundo patriarcal/capitalista/colonial/moderno". Ou seja, todo o conhecimento se situa, epistemicamente, ou no lado dominante, ou no lado subalterno das relaçóes de poder. Contudo, a neutralidade e a objetividade do conhecimento é um mito ocidental.

Grosfoguel (2008) ainda argumenta que, em termos históricos, isto permitiu ao Ocidente representar seu conhecimento como o único capaz de alcançar uma consciência universal, bem como dispensar o conhecimento náo ocidental por ser particularístico e, portanto, incapaz de alcançar a universalidade. Tal estratégia epistêmica foi crucial para a dominação e a expansáo coloniais europeias/euro-americanas que conseguiram construir, por todo o globo, uma hierarquia de conhecimento superior e inferior e, consequentemente, de povos superiores e inferiores. A partir desse entendimento, os estudos desenvolvidos por Sousa Santos (2008) propóem romper com esta lógica e considerar a diversidade excluída.

No campo da cooperaçáo internacional para o desenvolvimento, a distinçáo desses grupos é caracterizada pelos países centrais que afirmam deter o conhecimento científico e a tecnologia, e os países semiperiféricos e periféricos, que "recebem" estes conhecimentos como pressupostos para o "desenvolvimento". De tal modo, replica-se a colonizaçáo, por meio de dominaçáo ideológica, dos países semiperiféricos e periféricos pelos países centrais, em termos de conhecimento, ciência e tecnologia.

Essa relação de dominação intelectual dos países centrais com relação aos países periféricos replica-se nos projetos de cooperação internacional para o desenvolvimento. Segundo Milando (2005), no nível estratégico de indução do desenvolvimento, situam-se organizaçôes como o Fundo Monetário 
Internacional e o Banco Mundial, responsáveis pelo apoio técnico-financeiro externo no campo da cooperaçáo internacional. Tais organizaçóes definem o que deve ser feito a partir de reunióes técnicas e dossiês, imbuídas pela ideologia vigente nos países centrais.

É nas tentativas de transferência de "saber-fazer", entre o nível estratégico de indução do desenvolvimento e o nível local, que dois conjuntos de saberes e de significaçôes entram em relaçáo, geralmente em confronto: o embate entre os saberes técnicos (oriundos de um sistema de saberes técnico-científicos de origem ocidental) e os saberes populares (técnicos e náo técnicos) (DE SARDAN, 1995).

De Sardan (1995) explica que os saberes técnico-populares distinguem-se dos saberes técnico-científicos sob três perspectivas. A primeira perspectiva evidencia que os saberes técnico-populares sáo localizados, contextualizados, empíricos, ao mesmo tempo em que os saberes técnico-científicos são estandardizados, uniformizados, formalizados. A segunda perspectiva enfatiza que a relação entre esses dois tipos de saberes não é simétrica, ou seja, os saberes técnico-populares remetem aos conhecimentos do local, da populaçáo-alvo em que são aplicados os projetos e, por isso, estáo incluídos num mesmo sistema de sentido (ou cultura), enquanto que os saberes técnico-científicos são oriundos do "exterior", provêm de uma realidade eurocêntrica (cultura técnico-científica cosmopolita), como "pacotes prontos", difundidos pelos agentes do desenvolvimento, que não estão inseridos na cultura local. A terceira perspectiva ressalta que a posiçáo entre os saberes técnico-populares e os saberes técnico-científicos não é uma oposição entre uma "visão de mundo ocidental" e uma "visáo de mundo tradicional". Com efeito, tanto no meio rural africano quanto na Europa industrial, por exemplo, coexistem muitos sistemas de sentido e de interpretaçáo. Os saberes técnico-populares e os saberes técnico-científicos sáo somente dois sistemas possíveis, numa gama variável de saberes e de lógicas interpretativas que interagem.

Segundo Milando (2005), é preciso admitir que as populaçóes-alvo dos projetos de cooperaçáo internacional para o desenvolvimento são detentoras de conhecimentos profundos sobre as suas sociedades e que tais conhecimentos são essenciais para a eficácia e a sustentabilidade dos projetos de cooperação. Em outras palavras, é preciso reconhecer os saberes populares. 
Para superar esse embate, torna-se relevante pensar e promover a diversidade e a pluralidade, náo negligenciando ou recusando a ciência moderna, mas assegurando a coexistência de saberes ocidentais, com práticas de saberes locais, donde deriva a ecologia dos saberes. A ecologia dos saberes questiona a lógica da monocultura do saber e do rigor científico, a partir da identificaçáo de outros saberes e de outros critérios de rigor que operam em contextos e práticas sociais declarados náo existentes. Desse modo, a ecologia dos saberes visa criar uma nova forma de relacionamento entre o conhecimento científico e outras formas de conhecimento (SOUSA SANTOS, 2008). Esta proposta estaria mais alinhada à perspectiva da cooperaçáo Sul-Sul, a qual, idealmente, é apresentada como um processo de parceria entre países semiperiféricos e periféricos para fins de vantagens mútuas.

\section{Cooperação “Sul-Sul”: Ruptura Ideológica ou Reprodução?}

O debate teórico até aqui conduzido teve por objetivo aportar elementos, para que pudéssemos nos posicionar frente à questáo lançada já na introduçáo do presente artigo, a saber: a forma de cooperaçáo que vem ocorrendo entre os países periféricos, e entre esses e os semiperiféricos, ou seja, a chamada "Cooperaçấo Internacional Sul-Sul", estaria sendo pautada por um novo padráo de relaçóes internacionais, representativo de uma ruptura com o modelo de cooperaçáo Norte-Sul ou, se trataria apenas de uma nova modalidade de reprodução do sistema de dominação até entáo em vigor.

A análise dos elementos teóricos apresentados nos permite concluir: o modelo de cooperaçáo Norte-Sul é pautado por uma lógica utilitária e de competiçáo, no qual se pratica a transferência de conhecimento e tecnologia, de quem tem o saber para quem não tem saber. $\mathrm{O}$ que significa dizer: este modelo de cooperação pauta-se pelo modelo de dominação colonial ocidental/eurocêntrico, conforme teorizado por Sousa Santos (2008), Grosfoguel (2008), Dussel (2005), Quijano (2005) e Lander (2005).

Já no modelo de cooperaçáo Sul-Sul os países periféricos e semiperiféricos estabeleceriam redes de cooperaçáo e desenvolvimento que privilegiariam o reforço das capacidades entre os parceiros, via relaçóes horizontais, em que ambos se beneficiariam (XALMA, 2011). Nesse sentido, a cooperaçáo Sul-Sul seria pautada por uma lógica de reciprocidade, privilegiando a cooperaçáo e a compreensáo entre as pessoas, a solidariedade e o respeito à individualidade. 
A cooperação ocorreria em moldes participativos, dialógicos, compreendendo os diferentes sujeitos sociais, resgatando a dimensáo política e de emancipação do sujeito.

Em tese, a cooperaçáo internacional para o desenvolvimento, realizada entre países semiperiféricos e periféricos (CSS) estaria, pois, apoiada em uma visão de mundo que assume que o processo de cooperação para o desenvolvimento deve valorizar os conhecimentos, as habilidades e as competências locais, bem como a construçáo conjunta de tecnologias e a troca de experiências entre sujeitos dos países envolvidos na relação (XALMA, 2011; PUENTE, 2010; MILANDO, 2005; DE SARDAN, 1995). Posiçáo essa que contribuiria para se superar a dominaçáo ideológica, social, cultural e econômica da periferia e semiperiferia pelo centro (GROSFOGUEL, 2008).

Entretanto, há que se considerar que o modelo de cooperação Sul-Sul é construído com base no regime de acumulação capitalista e em um mundo pautado pelas concepçóes dominantes do sistema-mundo, as quais, conforme anteriormente analisado, estruturaram o modelo de cooperação Norte-Sul. Portanto, apesar das recursivas referências nos discursos dos cooperadores do Sul às preocupaçóes de natureza social, nos parece temerário afirmar que de fato a ética social esteja se sobrepondo aos interesses econômicos.

Todavia, é preciso reconhecer que se a priori seria profundamente arriscado afirmar que o Brasil, em suas relaçóes de cooperaçáo com outros países do Sul, estaria praticando um padrão de relaçóes com a supremacia dos valores humanistas sobre os interesses econômicos, também náo se pode obscurecer o fato de não termos uma história como país imperialista. O Brasil vem, sim, buscando agregar ao status de potência economicamente emergente, o destaque político. Processo esse no qual vem acumulando conquistas, como a recente nomeaçáo de um brasileiro para a presidência da Organizaçáo Mundial do Comércio (OMC). Conquista essa que tem incidência sobre o estado das relaçóes de força do sistema internacional, vislumbrando uma ampliação da multilateralidade. Por outro lado, não podemos comparar as intençóes dos países que aderem ao modelo de cooperaçáo Norte-Sul com as intençóes dos países que aderem ao modelo de cooperaçáo Sul-Sul. Embora situadas no campo político, as intençôes dos países emergentes, promotores da cooperaçáo Sul-Sul, buscam reestruturar o equilíbrio das forças no sistema mundial com foco na multipolaridade. 
Sob esse ponto de vista, Arrighi e Silver (2001, p. 25) comentam que:

Os conflitos entre civilizações surgem, em parte, porque a dominação ocidental sobre a economia política do planeta fomenta o ressentimento, ainda mais quando ela se torna veículo de propagação dos interesses, ideias e valores ocidentais. Mas a força mais importante por trás do futuro choque das civilizações é a mudança no equilibrio de poder civilizador causada pela modernização contínua do mundo não ocidental.

Todavia, será a análise dos dados coletados através da realização de estudos empíricos acerca das práticas de cooperaçáo internacional para o desenvolvimento Sul-Sul que poderão confirmar se esta modalidade de cooperação está, efetivamente, imbuída de uma lógica pautada por uma relaçáo dialógica, de proximidade e reciprocidade, respeitando a pluralidade de saberes e cultura locais. Estudos empíricos, que observem as práticas suprarreferidas, fazem-se, pois, fundamentais para que se possa responder ao enigma proposto no presente artigo.

\section{Referências}

AFONSO, M. M.; FERNANDES, A. P. ABCD introduçáo à cooperaçáo para o desenvolvimento. Lisboa: Instituto Marquês de Valle Flôr/Oikos, 2005.

ARRIGHI, G. Globalização e macrossociologia histórica. Revista de Sociologia e Política, Curitiba, no 20, p. 13-23, jun. 2003.

ARRIGHI, G.; SILVER, B. J. Caos e governabilidade no moderno sistema mundial. Tradução Vera Ribeiro. Revisão da traduçáo César Benjamim. Rio de Janeiro: Contraponto; Ed. da UFRJ, 2001.

AYLLÓN PINO, B. Transformaçóes globais, potências emergentes e cooperaçáo Sul-Sul: desafios para a cooperação europeia. Caderno CRH, Salvador, v. 25, n. 65, p. 233-249, 2012.

BARBANTI JR., O. Desenvolvimento e Relaçóes Internacionais. In: CAMPOS, T. L. C. (Org.). Desenvolvimento, desigualdades e relaçóes internacionais. Belo Horizonte: Ed. PUC Minas, 2005, p. 141-169.

CARDOSO, F. H.; FALLETO, E. Dependência e desenvolvimento na América Latina: ensaio de interpretação sociológica. 7. ed. Rio de Janeiro: Zahar, 1984.

CARRION, R. M. O lugar das organizaçóes náo governamentais em países de modernidade periférica. Projeto de pós-doutorado. Apoio CAPES, desenvolvido junto ao Institute de Recherche Sur le Développment /IRD. Paris 1, Sorbonne. 2009. 
CARRION, R. M. et al. Atores e discursos renovados para contradiçóes tradicionais? Em análise a cooperaçáo internacional para o desenvolvimento de Cabo Verde e Moçambique. In: COLÓQUIO INTERNACIONAL SOBRE PODER LOCAL, 12., 2012, Salvador. Anais... Salvador, 2012.

COBÉRIO, C. G. V. Os sistemas-mundo e a globalizaçáo. Race, Joaçaba, v. 7, n. 1, p. 53-70, jan./ jun., 2008.

DE SARDAN, J. P. O. Antropologie et development: essai en socio-antropologie du chagement social. Paris: Karthala, 1995.

DUSSEL, E. Europa, modernidade e eurocentrismo. In: LANDER, E. (Org.). A colonialidade do saber: eurocentrismo e ciências sociais: perspectivas latino-americanas. Buenos Aires: CLACSO, 2005. p. 24-32. (Colección Sur Sur).

GROSFOGUEL, R. Para descolonizar os estudos de economia política e os estudos pós-coloniais: transmodernidade, pensamento de fronteira e colonialidade global. Revista Crítica de Ciências Sociais, Coimbra, Portugal, n. 80, p. 115-147, 2008.

LANDER, E. Ciências sociais: saberes coloniais e eurocêntricos. In: LANDER, E. (Org.). A colonialidade do saber: eurocentrismo e ciências sociais: perspectivas latino-americanas. Buenos Aires: CLACSO, 2005. (Colección Sur Sur).

MIGNOLO, W. D. A colonialidade de cabo a rabo: o hemisfério ocidental no horizonte conceitual da modernidade. In: LANDER, E. (Org.). A colonialidade do saber: eurocentrismo e ciências sociais: perspectivas latino-americanas. Buenos Aires: CLACSO, 2005. (Colección Sur Sur).

MILANDO, J. Cooperaçáo sem desenvolvimento. Lisboa: Imprensa de Ciências Sociais, 2005.

PUENTE, C. A. I. A cooperaçáo técnica horizontal brasileira como instrumento de política externa: a evoluçáo da cooperaçáo técnica com países em desenvolvimento - CTPD - no período 1995-2005. Brasília, DF: FUNAG, 2010.

QUIJANO, A. Colonialidade do poder, eurocentrismo e América Latina. In: LANDER, E. (Org.). A colonialidade do saber: eurocentrismo e ciências sociais: perspectivas latino-americanas. Buenos Aires: CLACSO, 2005. (Colección Sur Sur).

RIBEIRO, M. T. F. Introdução. In: RIBEIRO, M. T. F.; MILANI, C. R. S. (Org.). Compreendendo a complexidade socioespacial contemporânea: o território como categoria de diálogo interdisciplinar. Salvador: EDUFBA, 2009.

ROSTOW, W. W. The stages of economic growth: a non-communist manifest. Cambridge: Cambridge University Press, 1960. 
SÁNCHEZ, E. R. Cooperación y desarrollo: nueve preguntas sobre el tema. Burgos, Espanha: Amycos, 2002. Disponível em: <http://www.ciberoamericana.com/documentos/introcoopdes/ Cooperacion_y_desarrollo_Nueve_pregunas_sobre_el_tema.pdf >. Acesso em: 19 jun. 2011.

SANTOS FILHO, O. dos. O fogo de Prometeu nas mãos de Midas: desenvolvimento e mudança social. In: CAMPOS, T. L. C. (Org.). Desenvolvimento, desigualdades e relaçóes internacionais. Belo Horizonte: Ed. PUC Minas, 2005.

SANTOS, B. S. Para além do pensamento abissal: das linhas globais a uma ecologia dos saberes. In: SANTOS, B. S.; MENESES, M. P. (Org.). Epistemologias do Sul. Coimbra, Portugal: Almedina, 2009.

A gramática do tempo: por uma nova cultura política. São Paulo: Cortez, 2008.

VISENTINI, P. O Brasil e a cooperaçáo Sul-Sul no pós-guerra fria. Políticas externas comparadas, relaçôes bilaterais e multilaterais com as "potências emergentes". Programa de Pós-Graduação em Relações Internacionais/UFRGS, 2008. Disponível em: <http://paulodaltro.blogspot.com. br/2008/12/o-brasil-e-cooperao-sul-sul-no-ps.html>. Acesso em: 5 mar. 2013.

WALLERSTEIN, I. The inter-state structure of the modern world-system. In: LINKLATER, A. (Ed.). Internacional relations: critical concepts in political science. London, New York: Routdledge, 2000.

World-system analysis: an introduction. Durham, London: Duke University Press, 2004.

XALMA, C. Report on South-South cooperation in Ibero-America 2011. Madrid: IberoAmerican General Secretariat (SEGIB), 2011.

Data de recebimento: 05.11 .2012

Data de aprovação: 16.09.2013

\section{South-South Development Cooperation under analysis: Paradigmatic Rupture or Reproduction?}

\section{Abstract}

The North-South model of international cooperation for development, whose origin refers to the period post II World War, relied historically, in a speech that attributed to core countries, or "North", given its institutional maturity and technical superiority, legitimacy to define the rules and procedures to be observed by countries on the periphery of the world system, to access the 
vaunted "development." This model, which as a significant contingent of researchers (BARBANTI JUNIOR 2005, SANTOS FILHO, 2005; AFONSO E FERNANDES, 2005; SÁNCHEZ, 2002), essentially contemplate goals of economic and political nature of the central powers. However, by winning recognition in the international economic, emerging countries such as Brazil, India, China, Russia and South Africa would be establishing between themselves as well as with other countries of the "South" partnership and cooperation to which also pursuant to a contingent of researchers (XALMA, 2011; PUENTE, 2010; AYLLON PINO, 2012), be distinguished from the previous model by the emphasis given to values such as solidarity and equity, regarding the equitable distribution of benefits among the countries involved in cooperation actions. Theoretical this article questions the extent to which this thesis is based? Or, to put it another way, to what extent international cooperation South-South model related to the promotion of the development is in a paradigmatic rupture with the North-South cooperation model?

Keywords: International Cooperation. South-South Cooperation. Development. 